\title{
Mechanisms underlying the cardiovascular effects of a labdenic diterpene isolated from Moldenhawera nutans in normotensive rats
}

\author{
Saad Lahlou ${ }^{\mathrm{a}, *}$, Carlos Antônio de Barros Correia Jr. ${ }^{\text {a }}$, Márcio Vasconcelos dos Santos ${ }^{\mathrm{d}}$, \\ Jorge Maurício David ${ }^{\mathrm{b}}$, Juceni Pereira David ${ }^{\mathrm{c}}$, Glória Pinto Duarte ${ }^{\mathrm{a}}$, \\ Pedro Jorge Caldas Magalhães ${ }^{\mathrm{d}}$ \\ a Department of Physiology and Pharmacology, Center of Biological Sciences, \\ Federal University of Pernambuco, 50670-901, Recife, Pernambuco, PE, Brazil \\ ${ }^{\mathrm{b}}$ Institute of Chemistry, Federal University of Bahia, Salvador, BA, Brazil \\ ${ }^{c}$ Pharmacy Faculty, Federal University of Bahia, BA, Brazil \\ ${ }^{\mathrm{d}}$ Department of Physiology and Pharmacology, Federal University of Ceará, Fortaleza, CE, Brazil
}

Received 1 March 2006; received in revised form 7 May 2006; accepted 14 June 2006

\begin{abstract}
Cardiovascular effects of Labd-8 (17)-en-15-oic acid (Labd-8), a labdenic diterpene isolated from methanolic extract of Moldenhawera nutans were investigated in normotensive rats. Additionally, this study examined the role of autonomic nervous system in the mediation of these cardiovascular effects. In pentobarbital-anesthetized rats, bolus intravenous (i.v.) injection of Labd-8 (1-10 mg/kg) induced dose-dependent hypotensive and tachycardiac responses. After cervical bivagotomy, hypotensive responses to Labd- 8 were significantly enhanced whereas the tachycardia was completely abolished. In conscious rats, Labd-8 (1-10 mg/kg, i.v.) also decreased blood pressure and increased heart rate in a dose-dependent manner. Pretreatment with methylatropine $(1 \mathrm{mg} / \mathrm{kg}$, i.v.) or propranolol ( $2 \mathrm{mg} / \mathrm{kg}$, i.v. $)$ significantly reduced the tachycardia evoked by Labd- 8 without affecting the hypotension. Blockade of ganglionic neurotransmission with hexamethonium ( $30 \mathrm{mg} / \mathrm{kg}$, i.v.) reduced and abolished the hypotensive and tachycardic effects of Labd-8, respectively. However, hypotensive effects of Labd- 8 were not reduced by pretreatment with $N^{\mathrm{w}}$-nitro-L-arginine methyl ester (L-NAME; $20 \mathrm{mg} / \mathrm{kg}$, i.v.), a nitric oxide synthase inhibitor. In rat endothelium-containing aorta preparations, Labd-8 $(1-1000 \mu \mathrm{g} / \mathrm{ml})$ induced a concentration-dependent reduction of potassium $(60 \mathrm{mM})$-induced contraction [IC 50 (geometric mean $\pm 95 \%$ confidence interval) $=313.6(191.4-513.8) \mu \mathrm{g} / \mathrm{ml}]$, an effect that remained unaffected $\left[\mathrm{IC}_{50}=440.8(225.1-863.3) \mu \mathrm{g} / \mathrm{ml}\right]$ by removal of vascular endothelium. These results show that i.v. treatment with Labd-8-induced dose-dependent hypotensive and tachycardiac effects in both conscious and anesthetized rats. The tachycardia is mediated reflexly through inhibition of vagal and activation of sympathetic drive to the heart. The hypotension is mainly due to withdrawal of sympathetic tone to the vasculature and also partly to an active vascular relaxation. Released nitric oxide from vascular endothelial cells is not involved in the mediation of Labd-8-induced hypotension.
\end{abstract}

(C) 2006 Elsevier Inc. All rights reserved.

Keywords: Autonomic nervous system; Cardiovascular effects; Isolated thoracic aorta; Labd-8(17)-en-15-oic acid; Leguminosae; Moldenhawera nutans; Rat

\section{Introduction}

Moldenhawera is a neotropical genus and it is distributed almost exclusively at the north coast of Brazil mainly in the Bahia State. It is represented by approximately 10 species (Queiroz et al., 1999). The taxonomy of this genus is confusing, making the classification of the species difficult (Lewis, 1987). Moldenha-

\footnotetext{
* Corresponding author. Tel.: +55 812126 8530; fax: +55 8121268976
}

E-mail address: lahlou@ufpe.br (S. Lahlou). wera nutans Queiroz and Alkin (Leguminosae) is a shrub apparently endemic of the coastal dunes of Salvador, State of Bahia. In a former phytochemical study with the stems of this species were reported the isolation and identification of several labdenic diterpenes (David et al., 1998), including labd-8(17)-en15-oic acid (Labd-8), 33,15-dihydroxy-labd-8(17)-ene, 19hydroxy-labd-8(17)-en-15-oic acid, and $3 \beta$-dihydroxy-labd-8 (17)-en-15-oic acid. None of these identified pure diterpenes showed the same activity exhibited by the methanolic extract $(72 \%$ at $200 \mu \mathrm{g} / \mathrm{ml})$ of $M$. nutans in the HIV-1 RT (p 66) assay 
(David et al., 1998). Very few studies have been addressed with $M$. nutans. Recently, a novel flavonol glycoside compound, laricetrin 5-gallaoy-3- $\beta$-D-xylopyranoside, has been isolated from the ethyl acetate extract of $M$. nutans leaves (do Vale et al., 2005). Unlike laricetrin, this novel compound showed any significant antioxidant activity in the 1,2-diphenyl-2-picryl-hydrazyl (DPPH) radicals scavenging test (do Vale et al., 2005).

The present investigation, which is comprised of two parts, was undertaken to assess the cardiovascular effects of Labd-8 (Fig. 1), the major labdenic diterpene found in the methanolic extract of M. nutans in rats (David et al., 1998). The first part was performed in conscious or anesthetized rats in order to assess the cardiovascular effects of Labd-8 and the role of the autonomic nervous system as well as the endothelial L-arginine/ nitric oxide (NO) pathway in the mediation of these effects. The second one was performed in vitro, using rat isolated thoracic aorta to assess whether the hypotensive effects of bolus injections of Labd-8 could result, at least in part, from its vasodilatory effects directly upon vascular smooth muscle.

\section{Materials and methods}

\subsection{Plant material}

Stems parts $(2.1 \mathrm{~kg})$ of $M$. nutans were collected on November 2000, at the Metropolitan Park area of Abaeté, Salvador, State of Bahia. Identification of the plant was confirmed by Prof. Maria Lenise da Silva Guedes (Institute of Biology, Federal University of Bahia). A voucher specimen (no. 029057) is deposited at the Alexander Leal Costa Herbarium, Institute of Biology, Federal University of Bahia. Labd-8 was extracted and isolated from the dried plant material according to previously reported procedures (David et al., 1998). Briefly, the dried plant material was first submitted to maceration with $\mathrm{MeOH}$ and the crude methanolic extract obtained $(270 \mathrm{~g})$ was immediately partitioned between hexane: $\mathrm{MeOH} / \mathrm{H}_{2} \mathrm{O}(9: 1)$ and $\mathrm{CHCl}_{3}: \mathrm{MeOH} / \mathrm{H}_{2} \mathrm{O}$ (6:4). The hexane partition (43.2 g) was then fractionated by gel silica column chromatography (CC) using hexane/EtOAc 95:5 as eluent. These procedures permitted to obtain the pure diterpene Labd$8(12.5 \mathrm{~g})$ from the second and third fractions $(125 \mathrm{ml})$ eluted from the CC. The structure of Labd-8 was identified by spectral analysis and the unequivocal assignment of NMR data was based on bidimensional experiments (David et al., 1998). The purity of Labd- 8 was $99.5 \% \mathrm{w} / \mathrm{w}$ as determined by GC/MS analysis.

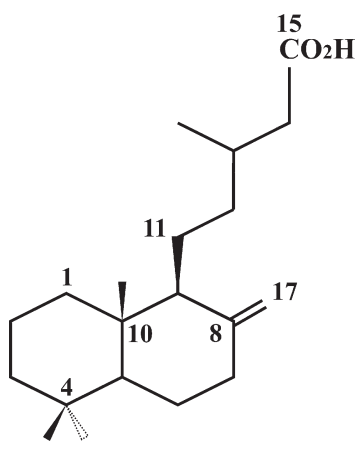

Fig. 1. Chemical structure of Labd-8(17)-en-15-oic acid.

\subsection{Animals}

Male Wistar rats were obtained from our local colonies maintained at the Department of Physiology and Pharmacology, Federal University of Pernambuco, Recife, Brazil. They were kept under conditions of constant temperature $\left(22 \pm 2^{\circ} \mathrm{C}\right)$ with a 12-h light-dark cycle and free access to food and water. All animals were cared for in compliance with the Guide for the Care and Use of Laboratory Animals, published by the US National Institutes of Health (NIH Publication 85-23, revised 1996; http:// www.nap.edu/readingroom/books/labrats/index.html) and had prior approval from the local animal ethics committee.

\subsection{In vivo experiments}

Rats (250-320 g) were anesthetized with intraperitoneally (i.p.) injected sodium pentobarbital $(50 \mathrm{mg} / \mathrm{kg}$ supplemented by an additional $15 \mathrm{mg} / \mathrm{kg}$ when necessary), and catheters (PE-10 fused to PE-50) were implanted in the abdominal aorta (for the recording of arterial blood pressure) and in the inferior vena cava (for drug administration) through the left femoral artery and vein, respectively. These catheters, filled with heparin-saline solution (125 IU/ml), were exteriorized at the dorsal neck level. Postoperatively, the rats received an intramuscular injection of penicillin $(24,000 \mathrm{IU})$, housed individually in plastic cages and allowed to recover for $24-48 \mathrm{~h}$ before any circulatory experiments. At the time of an experiment, the arterial catheter was connected to a blood pressure transducer (Statham P23 ID) coupled to a polygraph recorder; heart rate (HR) was obtained from a cardiotachometer triggered by the pressure pulses. Both signals were recorded on a Gilson model 5/6H polygraph (Medical Electronics Inc., Middletown, WI, USA). Mean aortic pressure (MAP) was calculated as diastolic $+[($ systolic - diastolic $) / 3]$.

Before each experiment, blood pressure and HR were allowed to stabilize and were recorded during 5-10 min (according to the duration of effects) after i.v. treatment with Labd-8. When subsequent doses of Labd- 8 were administered, MAP and HR were first allowed to return to their baseline levels, obtained before the first injection of the drug. When the effects of an antagonist were tested, antagonist injection occurred $10 \mathrm{~min}$ before Labd-8 administration. Only one antagonist was administered to any individual animal per day. Two series of experiments were performed as follows:

Series 1: This series of experiments was carried out in anesthetized rats to establish a dose-effect relationship. Rats were again anesthetized with sodium pentobarbital ( $50 \mathrm{mg} / \mathrm{kg}$, i.p.). The body temperature was maintained by an electric heating pad. After a stable MAP and HR was obtained, each animal received a series of increasing bolus (100 $\mu \mathrm{l})$ doses of Labd-8 (1, 3, 5 and $10 \mathrm{mg} / \mathrm{kg}$ ), via the i.v. catheter, and time-course of the changes in MAP and HR was recorded. These experiments were performed in both intact rats $(n=6)$, and in rats $(n=7)$ that had been subjected to a bilateral vagotomy performed at the cervical level $15 \mathrm{~min}$ earlier. In both intact $(n=3)$ and bivagotomized $(n=3)$ 
rats, the cardiovascular effects of 4 successive bolus $(100 \mu 1)$ injections of Ladb-8's vehicle, separated by a 10-min period interval, have been also determined.

Series 2: This series of experiments was performed in conscious rats to establish a dose-effect relationship and to assess the role of autonomic nervous system and NO in the mediation of cardiovascular responses to Labd-8. Therefore, time-course of the changes in MAP and HR elicited by i.v. injections of Labd- $8(1-10 \mathrm{mg} / \mathrm{kg})$ was determined in rats which had been pretreated intravenously $10 \mathrm{~min}$ earlier with one of the following pretreatments: vehicle $(1 \mathrm{ml} / \mathrm{kg}, n=6)$, methylatropine $(1 \mathrm{mg} / \mathrm{kg}, n=5)$ (Vasquez and Krieger, 1982), propranolol ( $2 \mathrm{mg} / \mathrm{kg}, n=5)$, hexamethonium $(30 \mathrm{mg} /$ $\mathrm{kg}, n=6)$ or L-NAME $(20 \mathrm{mg} / \mathrm{kg}, n=6)$. Each rat received increasing bolus doses as described previously and the cardiovascular effects of Labd-8's vehicle were also studied in conscious rats $(n=3)$ as described in Series 1. It should be noted that the dose $(30 \mathrm{mg} / \mathrm{kg})$ of hexamethonium chosen was sufficient to achieve complete ganglionic blockade (Sapru et al., 1982) and that of L-NAME was sufficient to block hypotensive effects of i.v. acetylcholine (Boussairi and Sassard, 1994). Doses of antagonists were chosen according to those recommended in the literature.

\subsection{In vitro experiments}

Rats were stunned and then exsanguinated. Thoracic aortae were removed and immersed in perfusion medium at room temperature. After removing adhering fat and connective tissue, the aorta was cut transversally into cylindrical strips $(1 \times 5 \mathrm{~mm})$, which were suspended in a 10-ml organ baths containing coninuously aerated perfusion medium at $37^{\circ} \mathrm{C}(\mathrm{pH}=7.4)$. Strips were stretched with a passive tension of $0.5 \mathrm{~g}$ and tension was recorded using an isometric transducer (Grass Model FTO3, Quincy, MA, USA) connected to a PC-based Dataq acquisition system (PM1000, CWE Inc., Akron, OH, USA). After an equilibration period of at least $60 \mathrm{~min}$, control contractions were induced by adding $60 \mathrm{mM}$ potassium chloride to the bath. When two successive control contractions showed similar amplitude, preparations were considered to be equilibrated. In order to assess the vasorelaxant effects of Labd- 8 on potassium-induced contraction, preparations were exposed to increasing concentrations $(1,3,10,30,100,300$, 600 and $1000 \mu \mathrm{g} / \mathrm{ml} ; n=6)$ of Labd-8 during 5 -min period once a sustained contraction elicited by a $60 \mathrm{mM}$ of $\mathrm{KCl}$ was established. Concentration-response curves to Labd- 8 were determined only once in each thoracic aorta preparation and Labd- 8 was directly added to the buffer solution in a cumulative manner.

In order to examine whether the vascular activity of Labd-8 is an endothelium-dependent effect, the vasorelaxant effects of Labd$8(1-1000 \mu \mathrm{g} / \mathrm{ml} ; n=5)$ were determined in preparations without functional endothelium. The endothelium was removed immediately after dissection by gentle rubbing of the aortic lumen with a stainless steel wire. Each endothelium-containing or endotheliumdenuded preparation was challenged at the beginning of the experiment with $1 \mu \mathrm{M}$ of acetylcholine, added on the plateau of a contraction induced by $30 \mathrm{mM} \mathrm{KCl}$. The absence of acetylcholineinduced vasorelaxant effects was taken as evidence that the preparation was effectively stripped of endothelium. In another set of experiments, endothelium-containing aorta preparations were also incubated with the same volume of Labd- 8 's vehicle as that used for the different concentrations of the diterpene. Contractions data were expressed as a percentage of the potassium-induced contraction.

\subsection{Drugs and solutions}

Sodium pentobarbital (Sanofi, Libourne, France) and heparin (Laboratoires Léo S.A., Montigny-le-Bretonneux, France) were used as commercially available injectable solutions. Methylatropine bromide, L-NAME, acetylcholine chloride, propranolol hydrochloride and hexamethonium bromide were purchased from Sigma Chemical Co. (St. Louis, MO, USA). Penicillin G benzathine salt was purchased from Lafepe (Recife, PE, Brazil). For in vivo experiments, Labd-8 was dissolved in Tween 80 (2\%), brought to the chosen volume with sterile isotonic saline and sonicated just before use. Methylatropine bromide, propranolol hydrochloride, L-NAME, and hexamethonium bromide were dissolved in saline just before use and administered in a volume of $1 \mathrm{ml} / \mathrm{kg}$ body weight. Each i.v. injection was followed by a $60-\mu \mathrm{l}$ (catheter volume) flush of physiological saline to ensure complete delivery of the dosage. For in vitro experiments, Labd-8 and acetylcholine were first dissolved in Tween and distilled water, respectively, brought to volume with Tyrode's solution, and sonicated just before use. The perfusion medium used was fresh modified Tyrode solution ( $\mathrm{pH}$ 7.4) of the following composition (mM): $\mathrm{NaCl} 136, \mathrm{KCl} 5, \mathrm{MgCl}_{2} 0.98, \mathrm{CaCl}_{2} 2, \mathrm{NaH}_{2} \mathrm{PO}_{4} 0.36$, $\mathrm{NaHCO}_{3}$ 11.9, and glucose 5.5.

\subsection{Statistical analysis}

All the results are expressed as means \pm standard error of the mean (S.E.M.). Maximal changes (expressed as a percentage of baseline values) in MAP and HR after each dose of Labd-8 were used to construct a dose-response curve. The $\mathrm{IC}_{50}$ value, defined as the Labd-8 concentration $(\mu \mathrm{g} / \mathrm{ml})$ required to produce half maximum reduction of potassium-induced contraction was used to evaluate vascular sensitivity to Labd-8. It was calculated by interpolation from semi-logarithmic plots, and expressed as geometric means [95\% confidence interval]. The significance $(P<0.05)$ of the results was assessed by means of paired and unpaired Student's $t$-tests, and one- or two-way analysis of variance (ANOVA), followed by Dunnett's post hoc test when appropriate.

\section{Results}

\subsection{In vivo experiments}

\subsubsection{Studies in pentobarbital-anesthetized rats}

In this series of experiments, baseline MAP and HR before injection of each dose of Labd-8 did not vary in magnitude $(P>0.05)$. Therefore, mean values of baseline MAP and HR in this group of animals were $108 \pm 2 \mathrm{~mm} \mathrm{Hg}$ and $363 \pm 10$ beats/ 
min, respectively (pooled data from 19). Intravenous injection of Labd-8 (1-10 $\mathrm{mg} / \mathrm{kg})$ induces immediate and dosedependent decreases in MAP $(P<0.001$, Fig. 2A), an effect that was associated to a tachycardia also dose-dependent $(P<0.001$, Fig. 2B). Hypotension and tachycardia responses to Labd- 8 occurred respectively within about 4 and $9 \mathrm{~s}$ after the injection of Labd-8 and became significant at the dose of 3 and $5 \mathrm{mg} / \mathrm{kg}$, respectively (Fig. 2A and B). After all doses tested of
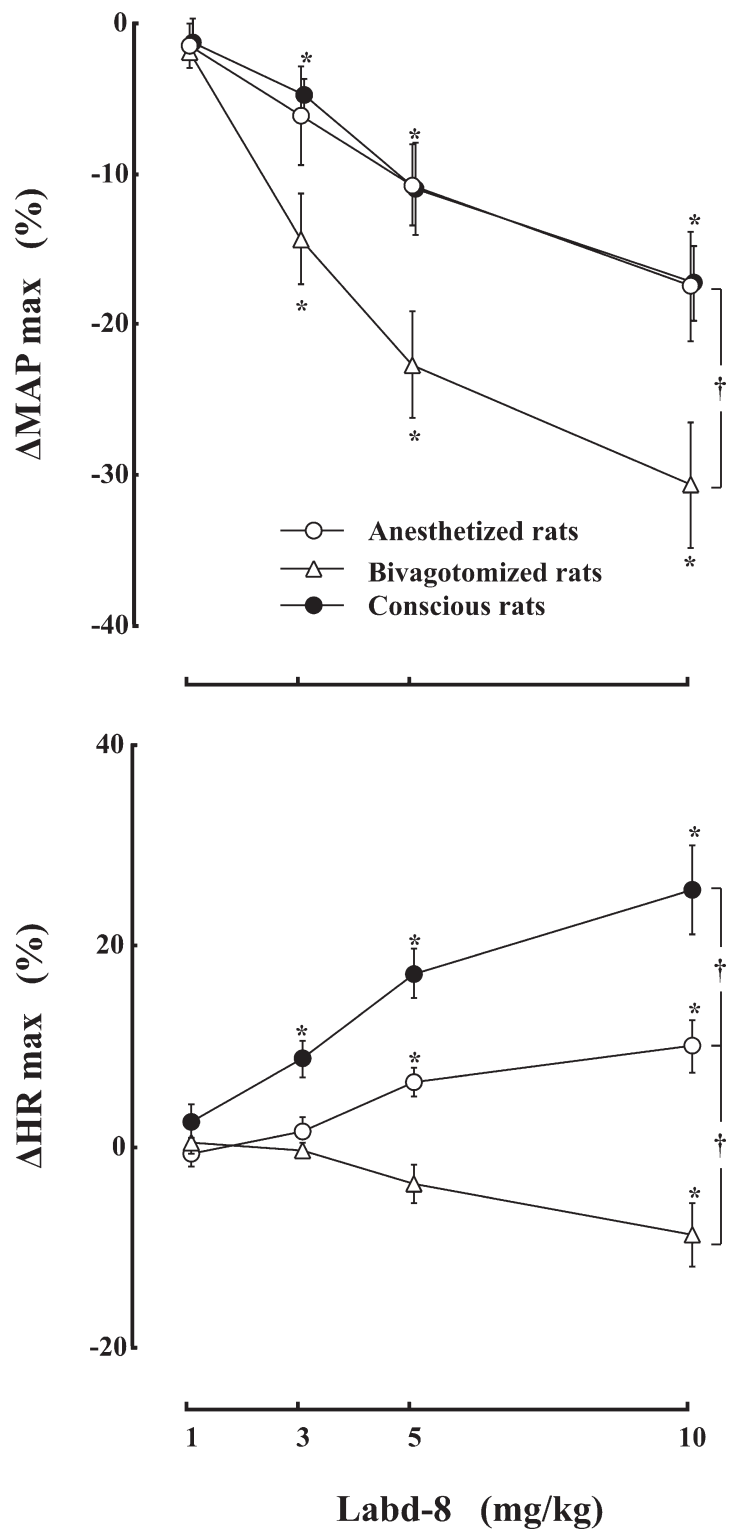

Fig. 2. Maximal decreases in mean aortic pressure ( $\triangle M A P \max , A)$ and heat rate $(\Delta \mathrm{HR}$ max, B) elicited by intravenous injection of increasing bolus doses (1$10 \mathrm{mg} / \mathrm{kg}$ ) of Labd-8(17)-en-15-oic acid (Labd-8) in pentobarbital-anesthetized rats with or without bilateral vagotomy, and in conscious vehicle-pretreated rats. Values are means of changes expressed as a percentage of baseline values. Vertical bars indicate S.E.M. (6-7 rats per group). The dose-hypotensive and dose-tachycardiac response curves for conscious rats pretreated with vehicle (from Fig. 3) were included here for comparison with those for intact, anesthetized rats. ${ }^{*} P<0.05$ by Dunnett's test with respect to basal values. ${ }^{\dagger} P<0.001$ by two-way ANOVA with respect to intact or bivagotomized, anesthetized rats.
Table 1

Maximal percent (\%) changes in baseline mean aortic pressure (MAP) and heart rate $(\mathrm{HR})$ elicited by 4 successive bolus $(100 \mu \mathrm{l})$ intravenous injections of Labd-8's vehicle in conscious rats (Group 1, n=3) and in anesthetized rats with (Group 2, $n=3$ ) or without (Group 3, $n=3$ ) cervical bivagotomy

\begin{tabular}{llrlrl}
\hline & Variable & $\begin{array}{l}\text { First } \\
\text { injection }\end{array}$ & $\begin{array}{l}\text { Second } \\
\text { injection }\end{array}$ & \multicolumn{1}{l}{$\begin{array}{l}\text { Third } \\
\text { injection }\end{array}$} & \multicolumn{1}{l}{$\begin{array}{l}\text { Fourth } \\
\text { injection }\end{array}$} \\
\hline Group 1 & MAP & $-0.80 \pm 0.80$ & $-0.40 \pm 1.52$ & $0.44 \pm 0.44$ & $-0.41 \pm 0.41$ \\
& HR & $2.21 \pm 1.17$ & $2.48 \pm 1.81$ & $2.70 \pm 2.02$ & $3.48 \pm 1.93$ \\
Group 2 & MAP & $1.28 \pm 0.67$ & $0.43 \pm 0.43$ & $-0.30 \pm 0.30$ & $0.27 \pm 0.27$ \\
& HR & $3.42 \pm 2.52$ & $1.87 \pm 3.75$ & $2.50 \pm 1.63$ & $1.20 \pm 0.80$ \\
Group 3 & MAP & $-0.20 \pm 0.31$ & $-0.17 \pm 2.04$ & $-1.79 \pm 1.79$ & $0.36 \pm 1.56$ \\
& HR & $1.10 \pm 1.10$ & $-0.88 \pm 0.88$ & $-0.82 \pm 0.82$ & $0.87 \pm 0.87$ \\
\hline
\end{tabular}

Labd-8, pre-dose values of both MAP and HR were fully recovered within the first 1 min following Labd-8 injection.

Bilateral vagotomy did not affect baseline MAP (109 \pm 2 vs. $106 \pm 2 \mathrm{~mm} \mathrm{Hg}$ in intact rats), but induced a significant $(P<0.05)$ increase in baseline HR ( $408 \pm 13$ vs. $372 \pm 11$ beats/min in intact rats). Bilateral vagotomy significantly enhanced the Labd- 8 dosehypotensive response curve $(P<0.001$, Fig. 2A). However, this treatment did not only completely abolish the Labd-8-induced tachycardia $(P<0.001$, Fig. $2 \mathrm{~B})$, but reversed it into a bradycardia that was significant $(P<0.05$, Fig. $2 \mathrm{~B})$ at the highest dose of Labd-8 (10 mg/kg). In both intact and bivagotomized rats, baseline MAP and HR values remained significantly unchanged following 4 successive i.v. bolus injections of Labd-8's vehicle (Table 1).

\subsubsection{Studies in conscious rats}

As in experiments with anesthetized rats, baseline MAP and HR values in conscious rats remained significantly unchanged following 4 successive i.v. bolus injections of Labd-8's vehicle (Table 1). Moreover, baseline MAP and HR before injection of each dose of Labd- 8 in conscious, vehicle-pretreated rats remained essentially invariant $(P>0.05)$. Therefore, mean values of MAP and HR in this group of animals before any pretreatment were $118 \pm 2 \mathrm{~mm} \mathrm{Hg}$ and $378 \pm 10 \mathrm{~b}$, respectively (pooled data from 31 rats). Only baseline MAP was significantly different from that measured in intact, pentobarbital-anesthetized rats $(P<0.05)$. In rats pretreated with vehicle, i.v. treatment with Labd-8 (1-10 mg/kg) also produced immediate and dosedependent hypotension and tachycardia $(P<0.001$, Fig. 3). These effects became significant at the dose of $3 \mathrm{mg} / \mathrm{kg}$ $(P<0.05$, Fig. 3$)$ and peaked at about $3-5 \mathrm{~s}$ after administration. After all doses tested of Labd-8, pre-dose values of both MAP and HR were fully recovered within the first $1 \mathrm{~min}$ following Labd-8 injection. Maximal percent increases in HR, but not the hypotension, elicited by Labd- 8 in conscious rats were significantly enhanced as compared to those recorded in pentobarbital-anesthetized rats $(P<0.05$, Fig. 2B).

Pretreatment with hexamethonium $(30 \mathrm{mg} / \mathrm{kg}$, i.v. $)$ induced significant $(P<0.001)$ decreases in baseline MAP $(88 \pm 6$ vs. $120 \pm 2 \mathrm{~mm} \mathrm{Hg}$ ) without affecting significantly baseline HR $(393 \pm 22$ vs. $398 \pm 14$ beats/min). However, pretreatment with methylatropine (1 $\mathrm{mg} / \mathrm{kg}$, i.v.) increased significantly $(P<0.001)$ the baseline HR $(452 \pm 17$ vs. $383 \pm 22$ beats $/ \mathrm{min})$ without affecting baseline MAP (115 \pm 4 vs. $115 \pm 5 \mathrm{~mm} \mathrm{Hg})$. 

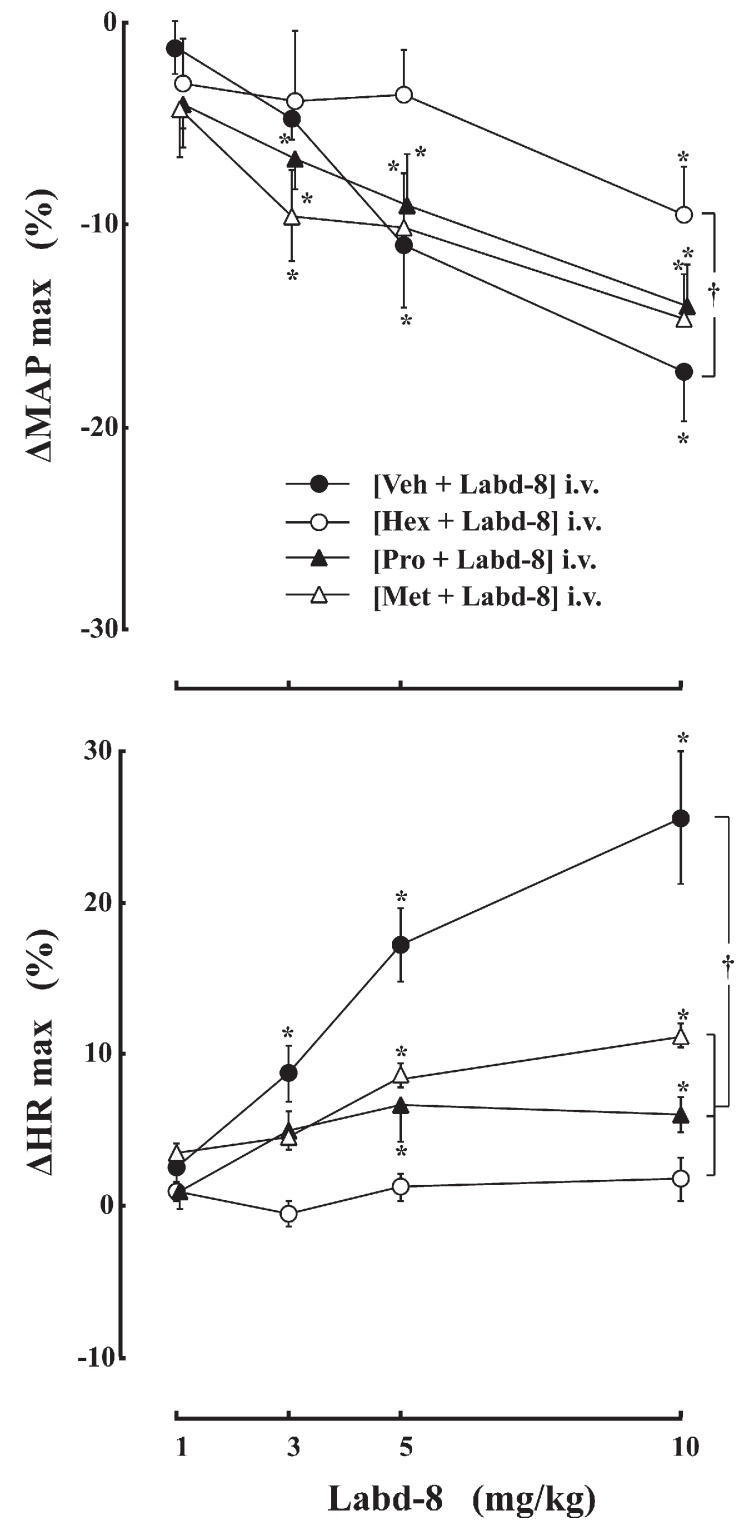

Fig. 3. Maximal decreases in mean aortic pressure ( $\triangle \mathrm{MAP}$ max, $\mathrm{A})$ and heart rate (HR max, B) elicited by intravenous (i.v.) injection of increasing bolus doses (1$10 \mathrm{mg} / \mathrm{kg}$ ) of Labd-8(17)-en-15-oic acid (Labd-8) in conscious rats subjected to i.v. pretreatment with vehicle (Veh; $1 \mathrm{ml} / \mathrm{kg}$ ), propranolol (Pro; $2 \mathrm{mg} / \mathrm{kg}$ ), hexamethonium (Met; $30 \mathrm{mg} / \mathrm{kg}$ ) or methylatropine (Hex; $1 \mathrm{mg} / \mathrm{kg}$ ). Values are means of changes expressed as a percentage of baseline values. Vertical bars indicate S.E.M. (5-6 rats per group). ${ }^{*} P<0.05$ by Dunnett's test with respect to basal values. ${ }^{\dagger} P<0.05$ by two-way ANOVA with respect to conscious, vehicle-pretreated rats.

Pretreatment with propranolol $(2 \mathrm{mg} / \mathrm{kg})$ decreased significantly $(P<0.001)$ baseline HR $(366 \pm 13$ vs. $413 \pm 24$ beats/ $\mathrm{min})$ but not baseline MAP $(118 \pm 5 \mathrm{vs} .118 \pm 5 \mathrm{~mm} \mathrm{Hg})$ values. Pretreatment with hexamethonium significantly $(P<0.05)$ reduced and abolished the hypotension (Fig. 3A) and tachycardia (Fig. 3B) elicited by Labd-8, respectively. The remaining hypotension was still significant $(P<0.05$, Fig. 3A) only at the highest dose of Labd- $8(10 \mathrm{mg} / \mathrm{kg})$. In rats pretreated with methylatropine or propranolol, the tachycardia evoked by Labd-8 was significantly and similarly reduced $(P<0.001$, Fig. 3B), whereas the hypotension remained unaltered (Fig. $3 \mathrm{~A})$. In these animals, the remaining tachycardia elicited by
Labd-8 (3, 5 and $10 \mathrm{mg} / \mathrm{kg})$ was still statistically significant with respect to baseline values $(P<0.05$, Fig. 3B).

Pretreatment with L-NAME $(20 \mathrm{mg} / \mathrm{kg}$, i.v. $)$ induced significant $(P<0.001)$ increases in MAP $(151 \pm 4$ vs. $115 \pm 3 \mathrm{~mm} \mathrm{Hg})$ and decreases in HR ( $232 \pm 9$ vs. $342 \pm 13$ beats $/ \mathrm{min})$. Blockade of nitric oxide synthase (NOS) by L-NAME significantly enhanced the dose-dependent decreases in MAP (Fig. 4A) and increases in HR (Fig. 4B) elicited by Labd-8 $(P<0.001)$.

\subsection{In vitro experiments}

In endothelium-containing aorta preparations, Labd-8's vehicle (Tween in Tyrode's solution) added to the bath at similar volumes as those used for the different tested concentrations of Labd-8 was without significant effects on the potassium

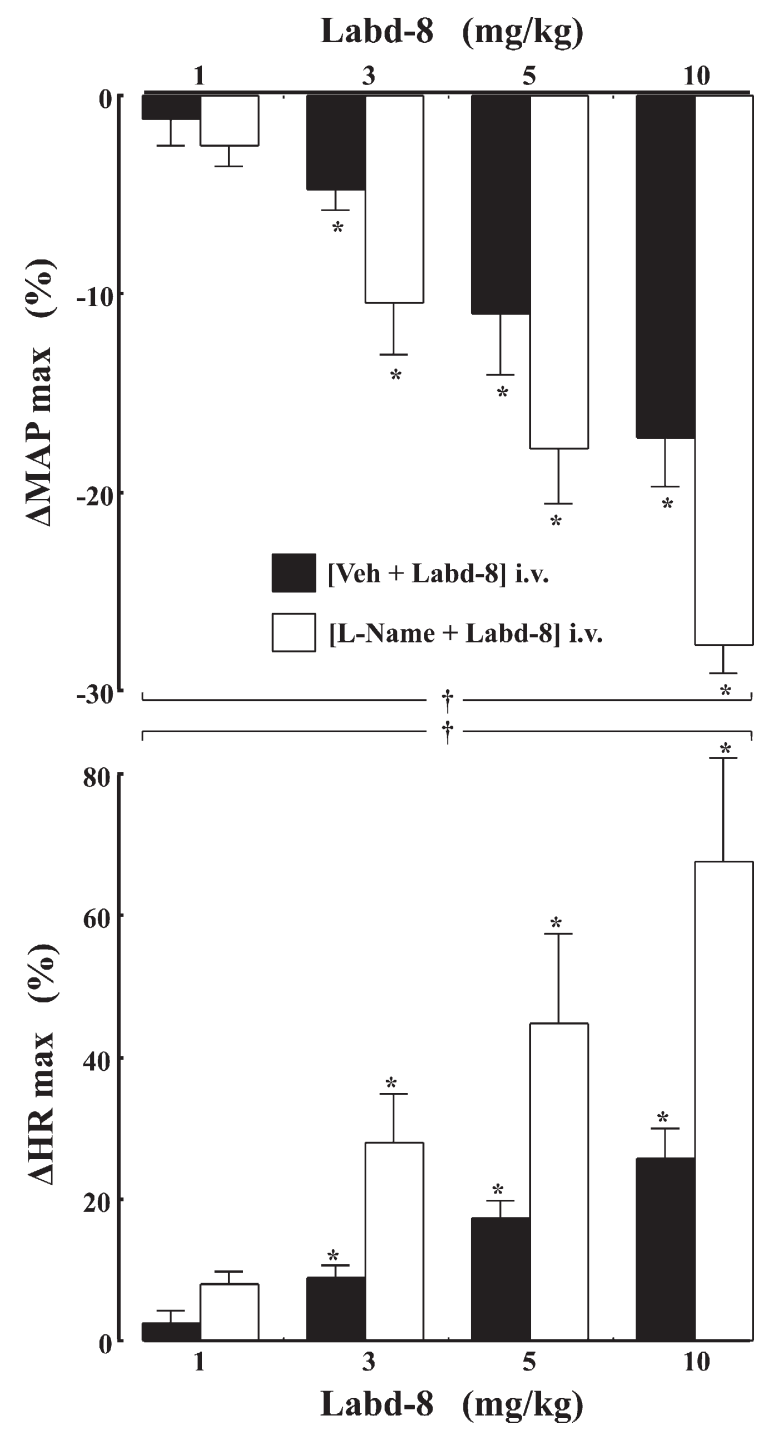

Fig. 4. Maximal decreases in mean aortic pressure ( $\triangle \mathrm{MAP}$ max, $\mathrm{A})$ and heart rate (HR max, B) elicited by intravenous (i.v.) injection of increasing bolus doses (1-10 mg/kg) of Labd-8(17)-en-15-oic acid (Labd-8) in conscious rats subjected to i.v. pretreatment with vehicle (Veh; $1 \mathrm{ml} / \mathrm{kg}$ ) or L-NAME $(20 \mathrm{mg} / \mathrm{kg})$. Vertical bars indicate S.E.M. (5-6 rats per group). For baseline MAP and HR see Results. ${ }^{*} P<0.05$ by Dunnett's test with respect to basal values. ${ }^{\dagger} P<0.001$ by two-way ANOVA with respect to conscious, vehicle-pretreated rats. 


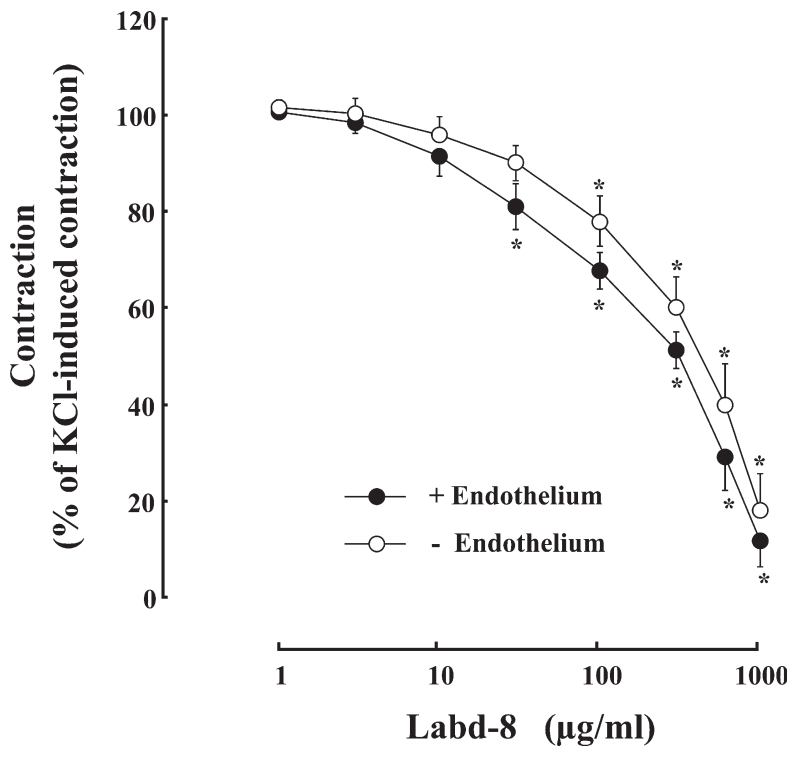

Fig. 5. Effects of increasing concentrations (1-1000 $\mu \mathrm{g} / \mathrm{ml})$ of Labd-8(17)-en-15oic acid (Labd-8) on the contraction induced by potassium $(60 \mathrm{mM})$ in rat isolated thoracic aortae with $(n=6)$ or without functional endothelium $(n=5)$. Vertical bars indicate S.E.M. ${ }^{*} P<0.05$ by Dunnett's test with respect to basal values.

(60 mM)-induced contraction, corresponding to $95.20 \pm 7.55 \%$ $(n=6)$ of control at the highest concentration $(0.4 \% \mathrm{v} / \mathrm{v})$ of Labd8 's vehicle used. However, KCl-induced contraction was significantly inhibited by Labd- $8(1-1000 \mu \mathrm{g} / \mathrm{ml})$ in a concentration-dependent manner $(P<0.001$, Fig. 5); the first inhibitory effect of Labd-8 became significant at a concentration of $30 \mu \mathrm{g} / \mathrm{ml}(P<0.05$, Fig. 5). This smooth muscle-relaxant activity of Labd-8 is independent upon the integrity of the vascular endothelium since the mean geometric $\mathrm{IC}_{50}$ values for Labd-8-induced reduction of potassium-evoked contractions were not significantly $(P>0.05)$ different in endotheliumdenuded preparations [313.6 (191.4-513.8) $\mu \mathrm{g} / \mathrm{ml}]$ when compared to those in preparations with intact endothelium [440.8 (225.1-863.3) $\mu \mathrm{g} / \mathrm{ml}]$.

\section{Discussion}

Baseline MAP and HR values of anesthetized or conscious, normotensive rats were of the same order of magnitude as those previously reported in the same preparation (Lahlou et al., 2004, 2005). The present study shows that i.v. treatment of either anesthetized or conscious rats with Labd-8, a labdenic diterpene isolated from methanolic extract of $M$. nutans, evoked an immediate and brief tachycardia (onset time of 6-9 s) that occurred coincidentally with arterial hypotension (onset time of 3-5 s). These cardiovascular effects are unrelated to Labd-8's vehicle as it had no significant effects on either baseline MAP or HR values. To the best of our knowledge, this is the first time that such cardiovascular effects of Labd- 8 have been reported in normotensive rats.

It is unlikely that the hypotension elicited by Labd-8 is mediated through activation of $\beta_{2}$-adrenergic vascular receptors since it remained significantly unaffected by propranolol pretreatment. However, blockade of ganglionic neurotransmission by hexamethonium significantly reduced the hypotensive response to Labd-8. This indicates that Labd-8 hypotension is partly dependent upon the presence of an operational central sympathetic neural drive to the vascular system. This sympathoinhibitory action of Labd-8 may be of a central origin and/or from a peripheral action at sympathetic ganglia and/or presynaptic sites. The current study, however, do not permit conclusions about the precise site of action of intravenously-administered Labd-8. Further studies are required to address this issue. On the other hand, the finding that the remaining hypotension after hexamethonium pretreatment is still significant at the highest dose $(10 \mathrm{mg} / \mathrm{kg})$ of Labd- 8 raises the possibility that Labd- 8 also may decrease blood pressure partly through its vasodilatory effects directly upon vascular smooth muscle. Such a hypothesis is corroborated by the present in vitro findings that Labd-8, but not its vehicle, induces a concentrationdependent vasodilator effect in endothelium-containing aorta preparations pre-contracted by $\mathrm{KCl}$. Such a smooth musclerelaxant activity of Labd-8 is independent upon the integrity of the vascular endothelium since the mean geometric $\mathrm{IC}_{50}$ values for Labd-8-induced reduction of potassium-evoked contraction were the same whether the aorta preparations were denuded or not. This observation contrasts with previous reported studies indicating the involvement of both endothelium-dependent and -independent mechanisms in the vasorelaxant effects of other diterpenes (Tirapelli et al., 2004a,b; Silva et al., 2005). The precise mechanism by which Labd-8 induces its endothelium-independent vasorelaxation requires further investigations.

It is well known that acetylcholine causes generalized vasodilatation, which is an indirect effect mediated by released NO from vascular endothelial cells (Furchgott and Zawadzki, 1980; Vanhoutte et al., 1995). The muscarinic receptor mediating relaxation of vascular smooth muscle, through released $\mathrm{NO}$, is the $\mathrm{M}_{3}$ subtype (Eglen et al., 1996). One might have suggested that the hypotension elicited by Labd- 8 would have been partly related to an active vascular relaxation mediated by an endothelial L-arginine/NO pathway through peripheral muscarinic receptor activation. However, such a possibility seems unlikely since (i) the hypotensive effect of Labd-8 was unaffected by i.v. pretreatment with methylatropine, a peripheral muscarinic receptor antagonist, (ii) the present in vitro findings show that vasorelaxant effects of Labd- 8 are mediated rather by an endothelium-independent mechanism, as they were unaffected by removal of vascular endothelium, and (iii) the hypotensive responses to Labd- 8 were not reduced by i.v. pretreatment with L-NAME. The mechanism of the increase in blood pressure by acute NOS inhibition is not clear. Although this effect is largely related to an impaired synthesis of NO at the arteriolar level, other central mechanisms involving activation of sympathetic tone or release of catecholamines from adrenal medulla have also been reported to play an important role (Togashi et al., 1992; Elayan et al., 2002; Huang et al., 2003). Thus, it is possible that the increased hypotensive effects of Labd-8 in L-NAME-pretreated rats are related to higher baseline MAP values and/or putative sympathetic outflow enhancement following NOS blockade by L-NAME. It is noteworthy that our preliminary results showed that i.v. injection of Labd-8 also elicited dose-dependent hypotensive 
and tachycardiac effects in conscious DOCA-salt hypertensive rats, in which basal sympathetic activity is increased. The latter finding together with that in L-NAME-pretreated normotensive rats is in line with our hypothesis that hypotensive effect of Labd- 8 is partly dependent upon the sympathetic vasomotor drive to the vasculature.

The hypotensive response evoked by Labd- 8 is associated to a dose-dependent tachycardia whether the animal was anesthetized or not. Several lines of evidence support the hypothesis that this tachycardia is of reflexogenic origin in response to the MAP decrease. First, its maximum magnitude occurred later than the peak of the hypotensive effect. Second, it was completely abolished in bivagotomized rats in which hypotensive response to Labd-8 was enhanced. Third, its magnitude was enhanced in rats pretreated by L-NAME in response to the enhancement of Labd- 8 hypotension recorded in these animals. Finally, the tachycardia was completely abolished by hexamethonium pretreatment, indicating that it is dependent upon the presence of an operational autonomic drive to the heart. This reflex tachycardia seems mediated by both vagal withdrawal and sympathetic activation. The involvement of vagal component is corroborated by the finding that Labd-8-induced tachycardia was abolished and significantly reduced by cervical bivagotomy and methylatropine pretreatment, respectively. The involvement of sympathetic component is corroborated by the finding that Labd-8 tachycardia was significantly reduced by either propranolol pretreatment or pentobarbital anesthesia. It is well known that the basal level of sympathetic nervous system activity is lower in anesthetized rats (Baum et al., 1985), and pentobarbital anesthesia depresses the baroreflex gain (Barringer and Bunag, 1990; Bedran-de-Castro et al., 1990; Shimokawa et al., 1998).

In conclusion, the current study shows that i.v. treatment of pentobarbital-anesthetized or conscious rats with Labd-8 results in dose-dependent hypotension and tachycardia, two effects that occur dependently. The tachycardia is of reflexogenic origin and depends upon the presence of operational and functional vagal and sympathetic drives to the heart. The hypotension is mainly due to a withdrawal of sympathetic vasomotor tone and partly to an active vascular relaxation. Released NO from vascular endothelial cells is not involved in the mediation of Labd-8induced hypotension. The present in vivo and in vitro findings are the first reported pharmacological effects of Labd- 8 on the cardiovascular system.

\section{Acknowledgements}

This work was supported by the Conselho Nacional de Pesquisa (CNPq) (Edital Universal), Instituto do Milênio do Semi-Árido (IMSEAR/MCT/CNPq) and the Federal University of Pernambuco (UFPE). CAB Correia Jr. and MV dos Santos are undergraduate students (PIBIC/CNPq fellow).

\section{References}

Barringer, D.L., Bunag, R.D., 1990. Differential anesthetic depression of chronotropic baroreflexes in rats. J. Cardiovasc. Pharmacol. 15, 10-15.

Baum, D., Halter, J.B., Taborsky, G.J., Porte, D., 1985. Pentobarbital effects on plasma catecholamines, temperature, heart rate, and blood pressure. Am. J. Physiol. 248, E95-E100.

Bedran-de-Castro, M.T., Farah, V.M., Krieger, E.M., 1990. Influence of general anesthetics on baroreflex control of circulation. Braz. J. Med. Biol. Res. 23, 1185-1193.

Boussairi, E.H., Sassard, J., 1994. Cardiovascular effects of basic fibroblast growth factor in rats. J. Cardiovasc. Pharmacol. 23, 99-102.

David, J.P., David, J.M., Yang, S.W., Cordell, G.A., 1998. A bis-labdenic diterpene from Moldenhawera nutans. Phytochemistry 50, 443-447.

do Vale, A.E., David, J.M., Brandão, H.N., David, J.P., 2005. A new flavonol glycoside derivative from leaves of Moldenhawera nutans. Z. Naturforsch. 60c, 45-49.

Eglen, R.M., Hedge, S.S., Watson, N., 1996. Muscarinic receptor subtypes and smooth muscle function. Pharmacol. Rev. 43, 109-142.

Elayan, H.H., Kennedy, B.P., Ziegler, M.G., 2002. L-NAME raises systolic blood pressure in the pithed rat by a direct adrenal epinephrine releasing action. Life Sci. 70, 2481-2491.

Furchgott, R.F., Zawadzki, J.V., 1980. The obligatory role of endothelial cells in the relaxation of arterial smooth muscle by acetylcholine. Nature 288, 373-376.

Huang, F., Villafaña, S., Hong, E., 2003. Role of central and sympathetic nervous systems in pressor effect of L-NAME. J. Cardiovasc. Pharmacol. 41, 68-72.

Lahlou, S., Figueiredo, A.F., Magalhães, P.J.C., Leal-Cardoso, J.H., Glória, P.D., 2004. Cardiovascular effects of methyleugenol, a natural constituent of many plant essential oils, in normotensive rats. Life Sci. 74, 2401-2412.

Lahlou, S., Magalhães, P.J.C., de Siqueira, R.J., Figueiredo, A.F., Interaminense, L.F., Maia, J.G., Souza, P.J., 2005. Cardiovascular effects of the essential oil of Aniba canelilla bark in normotensive rats. J. Cardiovasc. Pharmacol. 46, 412-421.

Lewis, G.P., 1987. Legumes of Bahia. Royal Botanic Gardens, Kew. pp. 30.

Queiroz, L.P., Lewis, G.P., Allkin, R., 1999. A revision of the genus Moldenhawera schrad (Legumonisae: Caesalpinoideae). Kew Bull. 54, 817-852.

Sapru, H.N., Gonzalez, E.R., Krieger, A.J., 1982. Greater splanchnic nerve activity in the rat. Brain Res. Bull. 8, 267-272.

Silva, R.M., Oliveira, F.A., Cunha, K.M., Maia, J.L., Marciel, M.A., Pinto, A.C., Nascimento, N.R., Santos, F.A., Rao, V.A., 2005. Cardiovascular effects of trans-dehydrocrotonin, a diterpene from Croton cajucara in rats. Vascul. Pharmacol. 43, 11-18.

Shimokawa, A., Kunitake, T., Takasaki, M., Kannan, H., 1998. Differential effects of anesthetics on sympathetic nerve activity and arterial baroreceptor reflex in chronically instrumented rats. J. Auton. Nerv. Syst. 72, 46-54.

Tirapelli, C.R., Ambrosio, S.R., da Costa, F.B., Coutinho, S.T., de Oliveira, D.C., de Oliveira, A.M., 2004a. Analysis of the mechanisms underlying the vasorelaxant action of kaurenoic acid in the isolated rat aorta. Eur. J. Pharmacol. 492, 233-241.

Tirapelli, C.R., Ambrosio, S.R., da Costa, F.B., de Oliveira, A.M., 2004b. Evidence for the mechanisms underlying the effects of pimaradienoic acid isolated from the roots of Viguiera arenaria on rat aorta. Pharmacology 70, 31-38.

Togashi, H., Sakuma, I., Yoshioka, M., Kobayashi, T., Yasuda, H., Kitabatake, A., Saito, H., Gross, S.S., Levi, R., 1992. A central nervous system action of nitric oxide in blood pressure regulation. J. Pharmacol. Exp. Ther. 262, 343-347.

Vasquez, E.C., Krieger, E.M., 1982. Decreased chronotropic responses to adrenergic stimulation following sinoaortic denervation in rat. Braz. J. Med. Biol. Res. 15, 377-387.

Vanhoutte, P.M., Boulanger, C.M., Mombouli, J.V., 1995. Endothelium-derived relaxing factors and converting enzyme inhibition. Am. J. Cardiol. 76, E3-E12. 